\title{
ELEMENTOS PARA UMA HISTÓRIA DAS RESISTÊNCIAS À PERÍCIA CRIMINAL: O CASO BAMBINO MARCHI, ROMA, 1925
}

\section{Elements to a history of resistances to criminal forensic: The Bambino Marchi Case, Rome, 1925}

\author{
Philippe Artières ${ }^{*}$
}

\begin{abstract}
RESUMO
A partir do estudo de um caso, o assassinato do jesuíta Paul Gény pelo soldado italiano Bambino Marchi, em 1925, o artigo pretende mostrar como uma escrita de cunho autobiográfico, o breve relato do crime escrito pelo próprio assassino, pode ser lida como uma forma de insurgência contra os discursos policiais e, principalmente, médico. Mais que mero exercício memorialístico, tal narrativa é uma verdadeira tomada de palavra contra a autoridade do perito.
\end{abstract}

Palavras-chave: perícia criminal, autobiografia, epilepsia psíquica

\begin{abstract}
From a study of a case, the murder of Jesuit Paul Gény, by italian soldier Bambino Marchi, in 1925, the article aims to show how a writing work with an autobiographical nature - the short crime story written by the killer himself - can be read as a form of insurgency against the police, and mainly medical speeches. More than a simple memorialist exercise, such narrative is a real word then against the forensic authority.
\end{abstract}

Keywords: criminal forensics, autobiography, psychic epilepsy

*CNRS-EHESS. E-mail para contato: ph.artieres@wanadoo.fr 
No dia 12 de outubro de 1925, o padre jesuíta Paul Gény, membro da Companhia de Jesus, é assassinado numa rua do centro de Roma por alguém chamado Bambino Marchi, um simples soldado italiano. Um conjunto de fontes estão disponíveis para tentar compreender esse evento. ${ }^{1}$ Dentre elas, há arquivos privados, que são familiares, mas também os de duas instituições: o da Companhia de Jesus (em Vanves, na França, e em Roma) e o da Universidade de Roma, onde Gény era titular da cadeira de filosofia ${ }^{2}$. Dispomos, assim, de um duplo corpus de artigos da imprensa contemporânea: um italiano e o outro francês. Por fim, nos arquivos da cidade de Roma existe um dossiê muito importante que conserva todas as peças do processo judicial. $^{3}$

Cruzando tais fontes, podemos estabelecer o que aconteceu na manhã do dia 12 de outubro de 1925 . Os sobrinho e sobrinha franceses de Paul Gény, residentes na França, estavam em Roma para lhe fazer uma visita. Tomado por seus diversos afazeres, ele não havia podido vê-los desde sua chegada. Um encontro foi marcado para o dia 12 , às $9 \mathrm{~h} 25$, para que passassem um dia juntos; estava previsto que tomassem um bonde e se encontrassem no lago de Nemi, na periferia da cidade santa. Mas os protagonistas não se encontraram, tendo os jovens esperado na estação de trem em vez da estação de bonde, que ficava próxima. Quando o bonde partiu, padre Gény foi à estação Termini onde os procurou; então ele foi ao colégio Massimo, onde foi diretor espiritual, para saber se seu sobrinho e sua sobrinha não o esperavam por ali. Não os tendo encontrado, parece que ele decidiu ir aonde eles se hospedavam, numa casa religiosa destinada aos peregrinos na via San Basilio. Foi então que ele cruzou com um soldado italiano que se pôs a segui-lo involuntariamente. Tendo chegado na rua San Basilio, deserta a essa hora, o militar se precipitou sobre ele e o assassinou com sua baioneta, por trás, pelo lado esquerdo da lombar, em seu coração. Cometendo seu crime, o

1 Sobre o crime como evento discursivo ver Dominique Kalifa, L'Encre et le sang. Récits de crimes et société à la Belle Époque. Paris: Fayard, 1995.

2 Entre suas obras, podemos ler: Paul Gény. Questions d'enseignement de Philosophie Scolastique. Paris: Beauchesne, 1913; ou ainda Paul Gény, Impressions de guerre, Etudes, 53e année, janvier-février-mars 1916.

$3 \mathrm{O}$ conjunto desses arquivos e das reproducões que fiz estão conservados hoje nos Arquivos da Academia francesa, em Roma. 
soldado, segundo algumas testemunhas, teria gritado as seguintes palavras: "Brutto pretaccio!", isto é, "Padre imundo!". O filósofo caiu na calçada, sem nenhum grito. Enquanto ele tentava se recompor, ele teria dito, em italiano, aos passantes que se aproximavam: "Rápido, chamem um frei capuchinho, mas imediatamente, pois vou morrer". Ele estava a quinze metros do $\mathrm{n}^{\circ} 8$ da Via San Basilio, para onde estava indo e que era muito próximo do convento dos Capuchinhos. Nesse momento, ele ainda tinha a baioneta enfiada no peito. Um policial apareceu, parou um carro, e este o transportou de pronto ao hospital San Giacomo. Ele perdera a consciência, mas ainda respirava. Na sala de operações, os dois médicos julgaram qualquer intervenção inútil. A ele foi dada a extrema unção e os óleos santos. Às $10 \mathrm{~h} 20$, estava morto.

$* * *$

Esse caso da morte de Paul Gény me levou a Roma em 2011 2012. Esse filósofo era meu tio-avô. Eu havia descoberto arquivos familiares relativos a sua obra e a seu assassinato; pus-me a investigar; escolhi o modo da narração pessoal para tratar desse evento. Escrevi um livro que se chamava Vie et mort de Paul Geny, publicado em 2013 pelas edições Seul, de Paris, na coleção "Fictions \& cie", dirigida pelo escritor e editor Bernard Comment. Historiador, decidi optar pela narração, por certo muito fragmentária, para analisar um crime na capital da cristandade no momento em que Mussolini ascendia ao poder. Inscrevia essa morte na história italiana contemporânea, mas também em minha própria existência. Eu encarnava a vítima e seu assassino, sucessivamente. Mobilizava arquivos e, com eles, tentava produzir uma história frágil na primeira pessoa.

Mais de cinco anos depois, nestas páginas que seguem, gostaria de voltar a esse caso propondo uma outra perspectiva de leitura que, à época, descartei. Proponho, portanto, uma nova visita ao caso Bambino Marchi. Trata-se de sugerir, rapidamente, a partir desse 
caso, alguns elementos para uma história das resistências à perícia criminal. Em meio a um trabalho já antigo - sobre um conjunto de autobiografias de criminosos de Lyon - eu havia tentando compreender como a perícia se comportava em face da injunção de verdade feita pelo médico ${ }^{4}$.

\section{O diagnóstico dos especialistas}

$\mathrm{O}$ ato do jovem soldado apareceu em um dos principais jornais italianos bem como no jornal católico francês La Croix, muito próximo dos meios católicos; mas o caso desapareceu rapidamente dos jornais, dado que era particularmente específico, levando-se em conta a vítima, alguém do meio universitário estrangeiro e pertencente a uma das ordens religiosas mais poderosas de Roma, a Companhia de Jesus. O contexto não era menos anódino: 1925 era um ano santo e a violência política dos jovens fascistas estava em plena expansão - nesses mesmos dias aconteceu em Florença uma noite de violências sem precedentes ${ }^{5}$. A ameaça anarquista e o arrastar-se da xenofobia constituíam dois riscos para as autoridades.

Não obstante essa atualidade, Bambino Marchi, no entanto, caiu rapidamente no esquecimento depois de sua prisão. $\mathrm{O}$ caso foi tratado pela justiça militar e pela promotoria de Roma ao mesmo tempo. No final da investigação, não houve processo e a imprensa, a respeito do caso, não falava mais do que de maneira breve.

A versão historicamente admitida, a que os redatores do volume "Jesuítas", do Dictionnaire du monde religieux (1985), dirigido por Jean-Marie Mayeur e Yves-Marie Hilaire, especifica, na notícia, que o assassino de Paul Geny havia confundido sua vítima com o emissário dos futuros acordos de Latrão entre o papa e Mussolini, o jesuíta Pietro Tacchi Venturi. Na verdade, se este último foi objeto de uma tentativa de atentado, isso ocorreu mais trade e não 
pelas mãos de Bambino Marchi. Além disso, à época tal razão jamais foi sustentada. $\mathrm{O}$ assassino não foi considerado como um anarquista, tampouco como um nacionalista; também não foi julgado pelo direito comum; foi declarado "demente no momento dos fatos" e, como consequência, irresponsável por seus atos aos olhos da lei. Não menos que três médicos peritos debruçaram-se sobre seu caso e também o examinaram. Eles redigiram relatórios imponentes conservados nos arquivos romanos e, por unanimidade, concluíram tratar-se de um caso de epilepsia delirante ${ }^{6}$.

São os trabalhos do doutor Paul Ardin-Delteil (1870-1929) ${ }^{7}$ que propõem a síntese mais precisa sobre a epilepsia em suas relações com o ato criminoso. Citaremos em profusão Ardin-Delteil a fim de compreender bem o que entendemos por epilepsia psíquica.

Esse médico explica notadamente que os dois caracteres inseparáveis de todo ato epiléptico são o automatismo e o impulso. Um movimento é chamado de automático etimologicamente quando aparece de maneira espontânea e, ao mesmo tempo é, segundo P. Janet, submetido "a um determinismo rigoroso, sem variações e sem caprichos." (p. 154-155). $1^{\circ}$ ) Ele não é o resultado e a transformação imediata de um impulso exterior atual, mas nasce, ou parece nascer, dele próprio; $2^{\circ}$ ) ele é um ato "sem vontade livre", o sujeito não pode modificá-lo a seu talante, o sujeito não é responsável por ele. E, segundo ele, sem dúvidas é a supressão da vontade - brusca, repentina, instantânea - que faz aparecer o caráter do impulso epiléptico.

O autor prossegue (p. 156) dizendo que se trata de uma "destruição radical da vontade livre, brutalmente suprimida, demolida pela explosão epiléptica; tal supressão brutal traduz-se pela brutalidade de uma invasão do automatismo". Todos os atos epilépticos com frequência têm a aparência de atos coordenados. No entanto, eles são impulsivos, o que dá ensejo a "uma série de caracteres novos: a) instantaneidade e energia na determinação dos atos, b) ausência de motivos (ou futilidade deles), c) ausência de

6 Laurence Guignard. Juger la folie. La folie criminelle devant les Assises au XIXe siècle. PUF. Coll. "Droit et Justice", 2010.

7 Paul Ardin-Delteil. L'épilepsie psychique: ses rapports dans l'aliénation mentale et la criminalité: épilesie larvée et equivalents épileptiques. Paris: J.B. Baillière et fils, 1898. 
premeditação, d) ausência de dissimulação (nenhum cuidado com esconder-se depois do atentado, que acontece à luz do dia), e) ausência de cumplicidade."; tais atos se fazem notar, por fim, pelo desenvolvimento de uma violência e de uma energia insólitas.

Além disso, eles são acompanhados por uma amnésia com, em certos casos, reminiscências parciais (p. 158 e seguintes). Outro traço característico aos olhos dos alienistas é a tendência quase constante a continuar andando, a fugir, a viajar. Dessa descrição também marcamos que "se o acesso psíquico estoura sem causa aparente, sem que nada o faça ser previsto, algumas vezes acontece de ele ser precedido de presságios que permitem prevê-lo e em parte dele retiram o caráter repentino." Mas o início do paroxismo não é menos brusco; "em meio a este céu escuro, escreve Ardin-Delteil, ignoramos quando irromperá o primeiro trovão."

A atitude de Bambino, notadamente a longa caminhada por Roma que o leva de seu quartel à via San Basilio, mas também o caráter repentino de seu ato, sua ausência de tentativa de fuga, fazem dele um criminoso epiléptico quase modelo. Uma das provas que teve um papel importante foi a fotografia que se encontrou na casa da família do acusado. Essa imagem, não datada, mostra um homem jovem, provavelmente nos arredores de sua pequena cidade, próximo de um poço, cigarro e sorriso na boca e, nas mãos, segura uma corda ligada a um corpo (é difícil saber se se trata de um corpo real ou de um manequim) que está suspenso. $\mathrm{O}$ outro elemento decisivo no diagnóstico dos médicos foi a doença mental da mãe e seu suicídio alguns anos antes dos fatos.

Bambino Marchi só deu justificativas muito incoerentes para seu ato, contradizendo-se aos olhos dos especialistas. Por todos esses elementos, classificou-se o dossiê considerando que o assassino era irresponsável e que ele deveria ser de imediato internado numa instituição psiquiátrica - o asilo de Reggio Emilia e seu célebre pavilhão de loucos criminosos estudados pelo historiador Mauro Bertani. ${ }^{8}$

8 Cf. Francesco Barale, Mauro Bertani, Vittorio Gallese, Stefano Mistura, Adriano Zamperini (org), Psiche. Dizionario storico di psicologia, psichiatria, psicoanalisi, neuroscienze, 2 vol. Torino: Einaudi, 2006/07. 


\section{Escrever para continuar a ser um sujeito histórico}

Alguns meses depois dessa decisão, que nasce da natureza de seu ato e, notadamente, de seu caráter anticlerical, Bambino Marchi procurou por diferentes meios se opor a ela. De fato, logo após sua prisão, o assassino declarara ter matado o religioso em razão da raiva que tinha de padres desde um episódio trágico da Primeira Guerra Mundial. Bambino tinha um irmão soldado no fronte; segundo ele, um dia o cura de um vilarejo veio anunciar a sua mãe que seu filho havia sido morto. A mãe, desesperada, suicidou-se. Mas a notícia era falsa e o irmão estava vivo e, algum tempo depois, retornaria. Bambino criou um fortíssimo rancor.

Não tendo sido compreendido, ele decidiu tomar sua caneta e escrever uma breve autobiografia; esta não foi suscitada pelos médicos como era por vezes o caso. $\mathrm{O}$ texto, que reproduzimos abaixo, é notável como uma verdadeira tomada de palavra contra a autoridade do perito. Não entraremos aqui na maneira como o autor argumenta, mas nos contentaremos em sublinhar que ele propõe uma outra leitura das circunstâncias do crime e, sobretudo, coloca em discussão o diagnóstico por meio de um discurso muito bem articulado.

Caro senhor professor Rodolfo Bonfiglio.

Segundo o desejo do tenente-coronel Consilio, eu gostaria de lhe informar sobre o que segue: no ano de 1927, escrevi uma longa carta ao professor Bertolani, vice-diretor do asilo para alienados de San Lazzaro, na província de Reggio Emilia, para refutar a perícia, de 1926, dos professores Saporito e Lapegna, realizada em Aversa. ${ }^{9} \mathrm{O}$ motivo de minha refutação era o fato de não me crer um epiléptico psíquico, como fui declarado por tal perícia.

$\mathrm{Na}$ minha carta eu reunia numa única mistura (intruglio) mentiras e verdade, fofocas e fatos, pelo simples motivo de que não

9 Bambino Marchi faz alusão ao exame psiquiátrico ao qual ele foi submetido no hospital judiciário de Aversa (província de Caserte), criado em 1876 e dirigido pelo professor Saporito a partir de 1907. 
gostaria de ter deixado uma pessoa, cuja grande retidão conhecia e que tem a obrigação de informar ao comissariado a respeito do conteúdo da supracitada carta, com o medo de provocar uma revisão e uma reabertura de minha instrução, como fatalmente, por diferentes motivos, teria acontecido.

Agora, eu renovarei a narrativa sincera do que aconteceu naquele fatal dia, e dos que o seguiram, suprimindo todas os floreios e mentiras que poderiam colocar sob falsa luz o que me proponho a escrever.

Eu descreverei da maneira mais breve minha vida passada.

Até os meus dez anos, isto é, quando morreu meu pobre pai, minha vida se passou mais ou menos como a das outras crianças. Inscrito na escola técnica, em pouco tempo me tornei um grande malandrinho (biricchino) para não dizer um verdadeiro canalha (lazzarone).

Em 1918, minha boa e querida mãe teve um ataque da chamada "gripe espanhola" que a deixou louca e a condenou ao suicídio. Então, o tempo passou, continuei minha vida de antes e, se eu não fazia maldades, tampouco fazia o bem e, em particular, não queria nem saber dos estudos. Para não estar de todo equivocado, eu brigava (provocavo un qualche attrito) com a família para então poder partir para longe com tristeza, mas sem ter sido maltratado por meus irmãos.

E assim vaguei por diversas cidades da Itália, dentre elas principalmente Veneza, de onde embarquei em um navio búlgaro, o "S.S. Costantin", e parti para a Inglaterra, chegando ao porto de Algeri (sic) sem no entanto desembarcar, indo descarregar carvão em Suderland, na Inglaterra, e, na sequência, me encontrava em Marselha, onde parei para em seguida voltar à Itália. Decidi me dedicar a algo no fim daquele mesmo ano me inscrevendo na Escola de agricultura $\mathrm{A}$ [ntonio] Zanelli ${ }^{10}$, em Reggio Emilia, onde consegui o segundo lugar. No ano seguinte, retornei à escola, mas depois das festas de Natal parti porque compreendi que não conseguiria terminar o curso, pois devia me apresentar no dia 30 de maio, em Roma, para o serviço militar.

Como o senhor sabe, em Roma eu fui colocado na Companhia ligada ao distrito e, depois de ter escrito ao distrito, fui enviado

10 Antonio Zanelli (1825-1894), agrônomo que em 1879 assumiu a direção da escola de agricultura especializada no estudo da produção de leite que, depois de sua morte, assumiu seu nome. 
para servir na segunda divisão territorial de Roma, situada na rua da Pilotta ${ }^{11}$.

Em 9/0/10 (abaixo da linha está escrito: outubro) tive um conflito com o sargento-mor Ruscani ou Russani, não me lembro bem.

Eu pensava ter razão e, esquecendo que estava diante de meu superior, levantei a voz e respondi como não poderia ter feito. Passado esse momento, esqueci o que aconteceu pensando que meu superior havia me perdoado. O que não aconteceu e, no dia 11, fiquei sabendo que havia sido punido com 5 dias de prisão estrita. O senhor não pode imaginar minha dor diante dessa notícia. Devia voltar à Companhia na mesma noite, mas consegui ser colocado em serviço e escapei da ordem durante todo o dia e a noite. No meio tempo, minha cabeça pensava na infelicidade que me chegava e não conseguia compreender que a falta havia sido inteiramente minha. Mas pensava apenas que era o sargento que me punia por simples gosto de se vingar de minhas respostas. Procurei esquecer e me pus a ler um livro que encontrei, as Aventuras de Rocambole, mas sem conseguir fazê-lo. Não saberia dizer se dormi pouco ou muito, me lembro apenas que o único pensamento que me surgia (no alto da linha está anotado: me acordava) no espírito foi a punição e fazer mal a quem a tinha me dado. Por medo de que ficando lá encontraria o sargento que me mandaria de volta à Companhia, saí dizendo que iria comprar cigarros para o general Barco. Mas, de fato, errei sem rumo por Roma para voltar mais tarde e retornar à divisão e pedir para que o capitão Caravaggi, oficial de ordenança do general Barco, suspendesse a punição que eu acreditava injusta. Meu espírito continuava a pensar e a maldizer quem para mim era a causa de tudo aquilo. Pensava que se fosse sargento como ele, e ele soldado como eu, levaríamos a questão a termo de outro modo. Por um duelo, aliás, isso me parecia a única solução possível.

$\mathrm{E}$ esses pensamentos que remoía provocaram os apropriados estados de alma e me conduziram, creio, a quase me ver mais uma vez diante de meu adversário e a pensar que se ele estivesse de fato ali, em carne e osso, teria sabido puni-lo como ele merecia. A ação seguiu as palavras e então adveio a catástrofe. Minha mão inconscientemente armada com o ponteiro da baioneta atingiu de modo fatal uma pessoa que caminhava diante

11 A Via della Pilotta (Rua da Pilotta) começa no cruzamento com a Via del Quattro Novembre, segue pelo Palácio Madama e desemboca na praça onde se situa a universidade Gregoriana 
de mim. O choque me fez retomar meus ânimos e vi diante de mim o terrível espetáculo de um padre que se contorcia e de uma mulher que gritava para mim: "assassino".

Permaneci como que tomado de estupidez e vendo dois policiais, corri em direção a eles dizendo: "eu matei".

Fui colocado numa viatura que me conduziu ao comissariado onde fui interrogado e onde dei a versão de meu delito que o senhor conhece melhor do que eu, pois o senhor pôde ter em mãos a declaração verbal, e, assim, dele tenho uma lembrança mais imprecisa. De lá fui conduzido à prisão de Regina Coeli ${ }^{12}$ onde fui interrogado para o julgamento de instrução cuja primeira declaração rejeitei.

Com as horas, como se meu [ato?] não fosse senão um pesadelo, esqueci.

- Ele me diz: "por que você não disse isso de pronto?"

Questão inútil.

$\mathrm{Eu}$ dei a primeira versão [aquela da vingança do suicídio de sua mãe e da raiva dos padres que a ele se seguiu] simplesmente porque, com as questões que me eram feitas, talvez as lembranças voltariam, admitindo que estas não estivessem já presentes, desde os eventos datando do suicídio de minha pobre mãe. Se minhas propostas se revelaram na sequência falsas, talvez tudo isso contribua para dar um tom de sinceridade àquilo que digo agora.

- Ele repetia para mim: "Mas você fala como uma pessoa que não sonha, mas que sabe que o que ela diz é verdade. Então você estava em plenas faculdades mentais."

- Por que não me deu a enfermidade total, então? Perguntei.

- Mas você declarou na sequência não se lembrar mais de nada!

- Isso é a verdade e está bem, mas se todo aquele que comete um delito e para ele dá um motivo, uma boa fé, e na sequência comparece dizendo não se lembrar de mais nada, é preciso enviálo para o sanatório. Mas isso é porque o senhor não acredita neles!

E porque o senhor acreditou na declaração.

Eu não sou presunçoso para querer dar lição, mas apenas digo: "Os professores Saporito e Lapegna não são dois charlatães e o senhor também não pode dizer que eu os comprei, porque, como para esta nova perícia, aceitei sem abrir a boca esses dois senhores colocados juntos pelo tribunal de Roma, porque sei

12 A prisão de segurança de Roma. 
perfeitamente que eles não dirão nada mais do que suas consciências e meu estado de sanidade mental os obriga a dizer. Eu sustento que o diagnóstico de meus peritos de Aversa é falso. Isto é, sustento que fazendo a soma dos prós e dos contras, eles se enganaram. Dar um nome à doença da qual sofria então, e talvez ainda hoje, somente este novo exame poderá dizer. Repito que não era um epiléptico psíquico.

O que sustento não diminui em nada seus prestígios, porque errar é humano.

Para terminar esta rápida revisita, é preciso enunciar o que tal empreitada, se desejamos desenvolvê-la não para um caso mas para um corpus mais amplo, exigiria. Parece-nos, de fato, muito importante, agora que conhecemos já há tempos e muito bem as teorias e as práticas na perícia criminal (notadamente graças aos trabalhos, em particular para a França, de Frédéric Chauvaud ${ }^{13}$ ), trabalhar sobre as formas de resistência à perícia, sobretudo sobre o que o sujeito periciado produz para opor uma outra versão de sua personalidade. Há um formidável campo de saber, construído na sombra da perícia psiquiátrica, que é preciso estudar; digo um saber e não aquilo que com muita frequência se considerou como argumentações individuais.

Tradução: Vinícius Nicastro Honesko

RECEBIDO EM: 15/05/2016 APROVADO EM: 20/06/2016

$13 C f$. Frédéric Chauvaud, Experts et expertise judiciaire. France, XIXe et XXe siècles. Rennes: PUR, Coll. Histoire, 2003; Les experts du crime. La medicine légale en France au XIXe siècle. Paris: Aubier, Coll. Historique, 2000, 301p. 